\title{
Human midbrain precursors activate the expected developmental genetic program and differentiate long-term to functional A9 dopamine neurons in vitro. Enhancement by Bcl- $X_{L}$
}

\author{
Emma G. Seiz . Milagros Ramos-Gómez , Elise T. Courtois , Jan Tønnesen , \\ Merab Kokaia , Isabel Liste Noya , Alberto Martínez-Serrano
}

\begin{abstract}
A B S T R A C T
Understanding the molecular programs of the generation of human dopaminergic neurons (DAn) from their ventral mesencephalic (VM) precursors is of key importance for basic studies, progress in cell therapy, drug screening and pharmacology in the context of Parkinson's disease. The nature of human DAn precursors in vitro is poorly understood, their properties unstable, and their availability highly limited. Here we present positive evidence that human VM precursors retaining their genuine properties and long-term capacity to generate A9 type Substantia nigra human DAn (hVM1 model cell line) can be propagated in culture. During a one month differentiation, these cells activate all key genes needed to progress from pro-neural and prodopaminergic precursors to mature and functional DAn. For the first time, we demonstrate that gene cascades are correctly activated during differentiation, resulting in the generation of mature DAn. These DAn have morphological and functional properties undistinguishable from those generated by VM primary neuronal cultures. In addition, we have found that the forced expression of $\mathrm{Bcl}-\mathrm{X}_{\mathrm{L}}$ induces an increase in the expression of key developmental genes (MSX1,
\end{abstract}

Abbreviations: A9-DAn, (dopaminergic neuron from the A9 group); 6-OHDA, (6-hidroxydopamine); DA, (dopamine);

DAn, (dopaminergic neuron); FB, (forebrain); FP, (floor plate); hESC, (human Embryonic stem cells); hNSC, (human neural stem cells); hVM, (human ventral mesencephalon); SNpc, (substantia nigra pars compacta); TH, (tyrosine hydroxylase); VM, (ventral mesencephaIon); VM DAn, (dopaminergic neuron from ventral mesencephalon); VM hNSC, (human neural stem cells from ventral mesencephalon) 
NGN2), maintenance of PITX3 expression temporal profile, and also enhances genes involved in DAn long-term function, maintenance and survival (EN1, LMX1B, NURR1 and PITX3). As a result, $\mathrm{Bcl}-\mathrm{X}_{\mathrm{L}}$ anticipates and enhances DAn generation.

\section{Introduction}

Dopaminergic neurons (DAn) of the ventral mesencephalon (VM) play essential roles in reward-based behaviors and control of voluntary movement, and the progressive loss of DAn from the A9 group (A9-DAn) of the Substantia nigra pars compacta (SNpc) causes motor impairments characteristic of Parkinson's disease (PD) [1,2]. Much effort has been done to identify the precursors of VM DAn and to understand the genetic cues and cascades controlling the development of VM DAn in experimental animals and humans. Such knowledge has the potential to improve the capacity to generate or engineer correctly differentiated human A9-DAn in vitro from their stem/precursor cells, and use them for basic studies, pharmacological drug screening and the development of cell replacement therapies [3-8].

VM DAn originate from precursors residing in the mesencephalic floor plate (FP), both in rodents and humans, which show features of radial glia [9-12], reviewed by [6,13-24]. In spite of the importance of identifying a well-characterized and reliable source of human A9-DAn, the present situation is that all neural stem/precursor cultures explored so far present numerous limitations. In addition, there is a large controversy on the actual capacity of various cultures derived from the fetal human VM to generate A9-DAn, in a stable manner [8,25-29]. In parallel to the work with non-immortal precursor cells, several groups, including ours, have recently developed immortalized cell lines of human neural stem/precursor cells (hNSCs), some of them derived from the fetal human VM (MESC2.10, NGC-407, ReNcell VM, vm c-mycER ${ }^{\mathrm{TM}}$ and hVM1) [30-34]. In these model cell lines, the non-transforming, immortalizing gene, $v$-myc overcomes the problem of limited expansion. The knowledge on the properties of the precursors being expanded in these cell lines, the preservation of their regional specification, and their capacity to activate correct genetic developmental programs, is very limited and uncertain, so far. In the present work, and using the hVM1 cell line as a model system, we have mainly aimed at defining in detail the molecular properties of, and the developmental steps taken by VM hNSCs when differentiating to A9-DAn (one month, long-term differentiation). This constitutes an essential step to fully understand the nature of the cells, and the means to proliferate them and preserve their neurogenic capacity.

In addition, we have investigated the potential effects that the forced expression of Bcl- $\mathrm{X}_{\mathrm{L}}$ may have on the properties of hVM1 cells and on their differentiation. The capacity of hNSCs and of human embryonic stem cells (hESCs) to generate DAn displaying the correct $\mathrm{A} 9$ phenotype is enhanced by $\mathrm{Bcl}-\mathrm{X}_{\mathrm{L}}$ [35-37]. Although a survival effect was attributed to $\mathrm{Bcl}-\mathrm{X}_{\mathrm{L}}$ in both systems, the enhanced expression of transcription factors related to DAn development has been investigated in the present work, to better understand Bcl- $\mathrm{X}_{\mathrm{L}}$ actions in VM hNSCs (hVM1 cells). Such knowledge will increase our understanding of the instability of VM precursor cells' properties in vitro, expand on the non-antiapoptotic functions of $\mathrm{Bcl}-\mathrm{X}_{\mathrm{L}}$ and help to replace its use with other interventions that would not pose safety hurdles, since blocking apoptosis could drive the cells closer to uncontrolled growth.

\section{Materials and methods}

\section{Cell culture}

VM hNSCs isolation, immortalization, culture, Bcl- $\mathrm{X}_{\mathrm{L}}$, forced expression and ethics permissions were previously described $[34,36]$. Briefly, the hVM1 cell line was generated from VM tissue of a 10 weeks post-conception old human fetus by $v$-myc immortalization [34]. Low passage number hVM1 cells were further modified to over-express $\mathrm{Bcl}-\mathrm{X}_{\mathrm{L}}$ [36]. The polyclonal cell lines naive hVM1 and the ones with the forced expression of $\mathrm{Bcl}-\mathrm{X}_{\mathrm{L}}$ are referred here as control or Bcl- $\mathrm{X}_{\mathrm{L}} \mathrm{hVM} 1$ cells. Detailed cell culture methods are provided under Supplementary information. Experiments were carried out using hVM1 cells at passage 9 to 12 , and $\mathrm{Bcl}-\mathrm{X}_{\mathrm{L}}$ cells at passages $25-30$, in order to work with cells with similar neurogenic potential (see the Results section). Mouse primary neuron cultures were obtained from VM of E12-E14 mice, following procedure detailed in [38].

\section{RNA extraction and Q-RT-PCR}

Total RNA was isolated from proliferating or differentiated cells using high pure RNA isolation kit (Roche, Basel, Switzerland). The cDNA was synthesized from $1 \mu \mathrm{g}$ of RNA using the high capacity cDNA Achieved kit (applied biosystems, Carlsbad, CA). Relative quantification of RNA expression was performed by TaqMan real time PCR using commercial probes described in Supplementary information, and was performed using the ABI PRISM 7900 HT Sequence Detection System as detailed in [36]. Calibrator samples to study the temporal expression profile of each gene in each cell line were day $0(\mathrm{~d} 0)$ samples. To study differences in the expression of a given gene between control and $\mathrm{Bcl}-\mathrm{X}_{\mathrm{L}}$ cells, hVM1 at d0 was taken as the calibrator sample and results are shown as the ratio hVM1 $\mathrm{Bcl}-\mathrm{X}_{\mathrm{L}} / \mathrm{hVM} 1$. The relative expression of a gene with respect to that of $\mathrm{TH}$ was defined as (gene of interest $\mathrm{RQ} / \mathrm{TH} \mathrm{RQ}$ ). All Q-RT-PCR data were obtained from biological triplicates, each run three times (technical triplicates).

\section{Immunocytochemistry (ICC) and western blotting (WB)}

Samples were processed following standard protocols $[34,36]$ and using antibodies described in Supplementary information.

\section{Morphometric analysis}

Neurite's morphology of $\mathrm{TH}^{+}$cells in cultures differentiated for $12-30$ day was analyzed as described [39]. A minimum of $50 \mathrm{TH}^{+}$ 
cells was photographed in randomly chosen fields for each sample and analyzed using NeuronJ/ImageJ (NIH, USA). The cell and processes were semi-automatically traced and assigned the status of primary, secondary, tertiary or quaternary neurites.

\section{Electrophysiology}

Functional properties of differentiated hVM1 Bcl- $\mathrm{X}_{\mathrm{L}}$ cells were evaluated by the whole-cell patch-clamp technique as described previously [40]. In short, cover slips with attached differentiated cells were transferred to a recording chamber continuously perfused at a rate of $3 \mathrm{ml} / \mathrm{min}$, at room temperature, with carbogenated $\left(95 \% \quad \mathrm{O}_{2} / 5 \% \quad \mathrm{CO}_{2}\right)$ artificial cerebrospinal fluid (aCSF). Resting membrane potential (RMP) was measured in current-clamp mode at $0 \mathrm{pA}$. Input resistance $\left(R_{i}\right)$ was assessed from $5 \mathrm{mV}$ square voltage pulses at RMP. For current/voltage $(I / V)$ relationship curves, we measured the membrane potential, while injecting $500 \mathrm{~ms}$ positive or negative currents stepwise. In some experiments tetrodotoxin (TTX, $2 \mu \mathrm{M}$ ) was added to the perfusion medium to confirm that action potentials were sodium channel-dependent. All data are presented as mean \pm standard error of the mean (SEM). Analyses for temporal changes were done by linear regression tests. Level of significance was set at $p<0.05$.

\section{Activity assays of dopamine transporter (DAT)}

\section{Dopamine reuptake}

Thirty-days differentiated control or Bcl- $\mathrm{X}_{\mathrm{L}}$ hVM1 cells and mouse VM primary neuronal cultures (E12, C57/BL6 mice, maintained for 1 week) were used to measure dopamine transport. Nomifensine (NMF, $10 \mu \mathrm{M}$, Sigma), a DAT inhibitor, was used to block unspecific transport. Cells (plus/minus NMF) were incubated with $50 \mathrm{nM}\left[{ }^{3} \mathrm{H}\right]-\mathrm{DA}$ (di-hydroxy-phenylethylamine 3.4 (ring-2,5,6-3H), 30-60 Ci/mmol, PerkinElmer, Waltham, MS) for $30 \mathrm{~min}$ at $37^{\circ} \mathrm{C}$. The reaction was stopped by removing the medium and washing the samples twice with PBS. Cells were lysed with $0.5 \mathrm{M} \mathrm{NaOH}$ and $0.2 \mathrm{ml}$ scintillation cocktail was added per well.

\section{Live cells imaging with 4-di-2-ASP}

$\mathrm{ASP}^{+}$(4-(-(diethylamino) stiril)- $\mathrm{N}$-methylpyrimidine iodide) is a fluorescent analog of 1-methyl-4-phenyl pyrimidine, a wellstudied neurotoxin transported by monoamine transporters. NMF was used to prevent binding to DAT in control samples. Cells were incubated with $0.5 \mu \mathrm{M} \mathrm{ASP}^{+}$(Invitrogen, Carlsbad, CA) for $15 \mathrm{~min}$ at $37^{\circ} \mathrm{C}$, and extensively washed with modified Tyrodes' solution. Trypan Blue ( $30 \mu \mathrm{M}$, Sigma) was added to the medium to reduce autofluorescence. Live cell images were collected using a confocal LSM510 inverted microscope coupled to an Axiovert200M (Zeiss) optical microscope. Fluorescence images (488 $\mathrm{nm}$ excitation, $607 \mathrm{~nm}$ emission) were mounted off-line onto the corresponding bright field images.

\section{Treatment of cultures with 6-hydroxydopamine (6-OHDA)}

Differentiated $(30 \mathrm{~d})$ control and Bcl- $\mathrm{X}_{\mathrm{L}}$ hVM1 cells were treated with $50 \mathrm{mM} \mathrm{6-OHDA} \mathrm{(Sigma)} \mathrm{in} \mathrm{the} \mathrm{presence} \mathrm{or} \mathrm{absence} \mathrm{of}$ $10 \mu \mathrm{M}$ NMF (Sigma) for 1,2 or 3 days. Afterwards, the cells were fixed and immunostained for $\mathrm{TH}$ to assess the percentage of surviving DAn. $\mathrm{TH}^{+}$cells were counted in an Axiovert200 microscope (Zeiss) at $40 \times$.

\section{Statistical analyses}

All data are shown as means \pm SEM of at least three independent experiments. Data were analyzed by ANOVA followed by the appropriate post-hoc test (Instat 2.03, Graph Pad Software).

\section{Results}

\section{Forebrain and VM hNSCs preserve their different regional information}

Preservation of the regional properties in long term-cultured hNSCs is not granted. Therefore, the expression levels of two very early neuroectoderm markers (PAX6, EN1) and of SNpc genes (TH, DAT, GIRK2) were studied in FB and VM hNSCs (human neural stem cells) (Fig. 1A). PAX6, a determinant of neuroectoderm fate, was expressed at higher levels in FB than in VM cells. EN1, a transcription factor characteristic of the midbrain neuroepithelium, was expressed at two orders of magnitude higher levels in hVM1 than in hNS1 cells. In parallel, TH and DAT expression was substantially higher in hVM1 cells, and, most importantly, GIRK2 expression, typical of A9 DA neurons, was differentially expressed at much higher levels in VM than in $\mathrm{FB}$ cells. hVM1 cells also expressed OTX2 and SOX2 (Supplementary information Fig. 1).

We have reported that DAn generation from VM hNSCS decreases with passaging, and that neurogenesis is enhanced and stabilized after forced expression of $\mathrm{Bcl}^{-\mathrm{X}_{\mathrm{L}}}[35,36,41,42]$. Since in the present study we wanted to work with hNSCs producing neurons ( $\beta$-III-tubulin ${ }^{+}$) at the same rate, to focus on the dopaminergic phenotype, we chose to work with different passage numbers of control and Bcl- $\mathrm{X}_{\mathrm{L}}$ hVM1 cells (9-12 and $25-30$, respectively), generating in each case approximately $20 \%$ neurons ( $\beta$-III-tub ${ }^{+}$, Fig. $1 \mathrm{~B}$ and $\mathrm{C}$ ). In the same cultures, the rate of $\mathrm{TH}^{+}$neuron generation was increased in $\mathrm{Bcl}-\mathrm{X}_{\mathrm{L}}$ cells in comparison to control ones by $30 \%$ at $\mathrm{d} 7$ and $100 \%$ ( 2 -fold) at $\mathrm{d} 30$ of differentiation (Fig. $1 \mathrm{C})$. The cholinergic $\left(\mathrm{ChAT}^{+}\right)$phenotype was not detected throughout the experiment and serotonergic $\left(5-\mathrm{HT}^{+}\right)$neurons were only occasionally found (less than $0.01 \%$ ). As expected for VM precursors, the cultures generated $4.05 \% \pm 0.56 \mathrm{GABA}^{+}$and $1.94 \% \pm 0.26$ Glutamate $^{+}$neurons.

\section{Expression of proneural genes at early differentiation times}

In FB hNSCs mitogen withdrawal triggers differentiation, and thus the percentage of nestin and $\mathrm{Ki}-67$ positive cells decreases to about $20 \%$ by d7 [42]. In hVM1 cells, differentiation is accompanied by the disappearance of nestin ${ }^{+}$cells (NSCs), and the exit of the majority of the cells in culture from the cell cycle (becoming Ki-67 negative) (Supplementary information Fig. 2). $\mathrm{Bcl}-\mathrm{X}_{\mathrm{L}}$ did not induce any significant change at any time point or marker studied, but for a trend for a faster disappearance of nestin ${ }^{+}$cells.

Simultaneously, during the first week of differentiation, the human homologues of three proneural genes known to have 

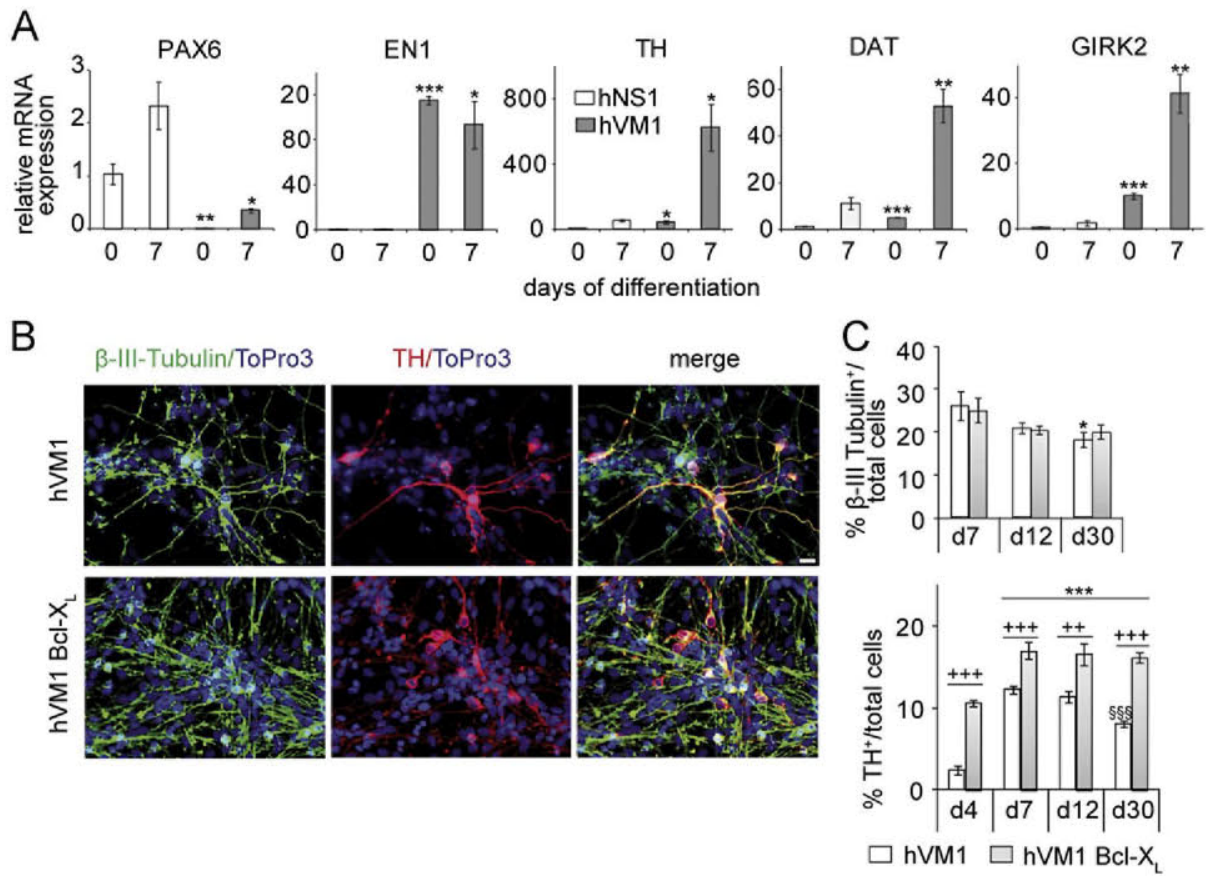

Fig. 1 - Regional identity and basic phenotypical properties of hVM1 cells. (A) Q-RT-PCR of genes related to central nervous system regionalization. Results are mean \pm SEM $(n=3)\left({ }^{*} p<0.05,{ }^{* *} p<0.01,{ }^{* * *} p<0.001\right.$, compared to hNS1 d0; $t$-test). (B) Immunocytochemical staining for $\beta$-III-Tubulin (green) and TH (red) in 30 day differentiated hVM1 and hVM1 Bcl- $\mathrm{X}_{\mathrm{L}}$ cultures.

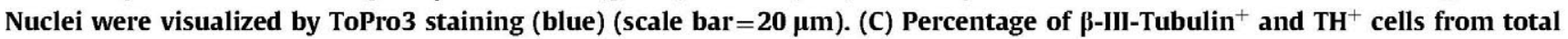
cells in differentiated cultures. Note the decrease in both neurons and $\mathrm{TH}^{+}$neurons from $\mathrm{d} 7 \mathrm{to}$ d 30 in control hVM1 cells. Data were obtained from triplicate experiments and are expressed as mean \pm SEM. Stats: ANOVA followed by post-hoc Tukey test ( $\beta$-III-

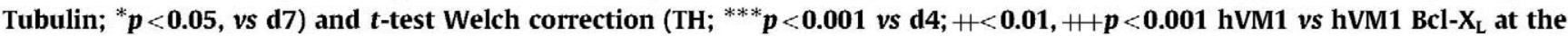
indicated day; $\S \S \S<0.001 v s$ previous day for each cell line). (For interpretation of the references to color in this figure legend, the reader is referred to the web version of this article.)

crucial roles in the development of midbrain neurons in the mouse (Mash1, Msx1 and Neurogenin2 (Ngn2)) have been studied (Fig. 2). Whereas Mash1 is a general proneural gene, thought to act in a permissive manner (that is, dispensable, not required nor sufficient for DAn generation), Msx1 and Ngn2 are essential for the correct development of VM DAn [6,17,18,23,27,43-47].

A) Temporal expression (data from each cell type compared to levels at d0): We have previously shown that MASH1 and NGN2 expression become activated with differentiation in control hVM1 cells [34]. Here (to assure consistency between studies) we have reproduced those findings (activation of MASH1 expression and the transient expression of NGN2 (peaking at d4) in hVM1 control cells) (results not shown). In the case of MSX1, parallel to MASH1, there is an increase in its expression along a one-week differentiation in control cells (Fig. 2A). In Bcl- $\mathrm{X}_{\mathrm{L}}$ cells the time course of expression of MASH1 and NGN2 was unaltered, but there was a clear anticipation of the peak levels of MSX1 (by d4).

B) Net Bcl- $X_{L}$ effects on gene expression levels: When the expression data were compared at each day being $B c l-X_{L}$ the only variable (Fig. 2B) we found that there was an one order of magnitude enhancement of NGN2 levels present at d0 and d7 (not shown, see also Ref. [34]), and that MSX1 levels were significantly increased around 15 -fold by Bcl- $\mathrm{X}_{\mathrm{L}}$ at $\mathrm{d} 4$, what may be determinant for an enhanced DAn generation.
Expression of pro-dopaminergic transcription factor genes at early differentiation times

EN1, LMX1B, NURR1 and PITX3 are needed for the correct development of VM A9-DAn [6,17], and were studied in parallel to $\mathrm{TH}$ (tyrosine hydroxylase, the rate limiting enzyme in catecholamine biosynthesis; serving here as a reporter of the presence of DAn).

A) Temporal expression (data from each cell type compared to levels at d0): All studied genes, but PITX3, showed a similar time course of expression between the control and $\mathrm{Bcl}-\mathrm{X}_{\mathrm{L}}$ cells (Fig. 3A). EN1 expression remained nearly constant during the one week of differentiation, as expected, whereas LMX1B, NURR1 and TH progressively increased their expression levels in both cell types, consistent with the earlier expression of proneural genes (Fig. 2). Note that the expression levels of LMX1B, NURR1 and PITX3 by $\mathrm{d} 4$ are only different from those at $\mathrm{d} 0$ in the Bcl- $\mathrm{X}_{\mathrm{L}}$ cells. The case of PITX3 was interesting since the control cells expressed it, but did not up-regulate the gene, even by $\mathrm{d} 7$ (and even later, see below). This aspect could be important to explain a lower yield of DAn in the control cultures, when compared to $\mathrm{Bcl}-\mathrm{X}_{\mathrm{L}}$ ones.

B) Net Bcl- $X_{L}$ effects on gene expression levels: When the expression data were compared at each day being $\mathrm{Bcl}-\mathrm{X}_{\mathrm{L}}$ the only variable (Fig. 3B) we found a number of interesting 
differences between control and Bcl- $\mathrm{X}_{\mathrm{L}}$ cells. First, as expected from the increased number of $\mathrm{TH}^{+}$neurons in $\mathrm{Bcl}-$ $\mathrm{X}_{\mathrm{L}}$ cells at $\mathrm{d} 7$ (Fig. $1 \mathrm{C}$ ), we observed $\mathrm{a} \approx 4$-fold increase in $\mathrm{TH}$ mRNA levels induced by $\mathrm{Bcl}-\mathrm{X}_{\mathrm{L}}$. This was accompanied and possibly explained by the increased levels of all other genes in Bcl-X $X_{\text {L }}$ cells: EN1 ( $\approx 1.5$-fold by d0), LMX1B ( $\approx 5$-fold by d7), NURR1 $(\approx 2$-fold by $d 7)$ and particularly PITX3 $(\approx 10$-fold enhancement by $d 4$, just the time when its expression is

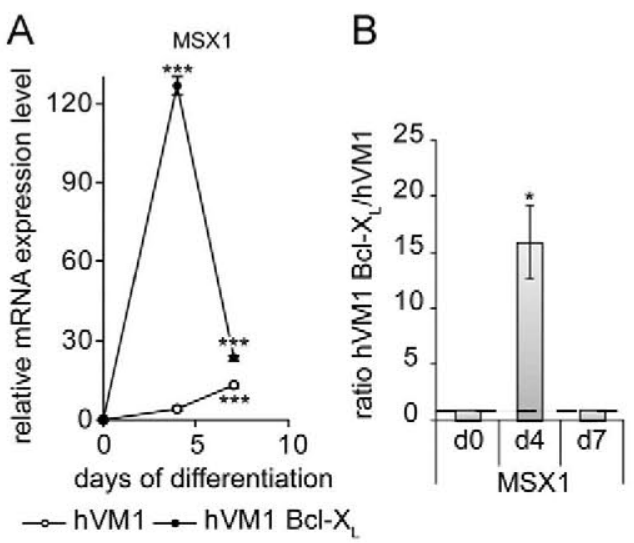

Fig. 2 - Expression of proneuronal genes during early differentiation times. (A) Temporal gene expression profile of MSX1 in each cell line determined by Q-RT-PCR (see legend of Supp. Info. Fig. 1 for detailed calculations). Results are mean \pm SEM $(n=3)\left({ }^{*} p<0.05,{ }^{* * *} p<0.001\right.$ vs d0; $t$-test). (B) $B c l-X_{L}$ effects on relative MSX1 mRNA levels expressed as ratio hVM1 Bcl- $X_{L} / h V M 1$ at each studied day (see legend of Supp. Info. Fig. 1 for detailed calculations). Results are mean \pm SEM $(n=3)\left({ }^{*} p<0.05\right.$, indicates significant differences to 1 (equal values); one sample $t$-test). needed, to cooperate in the generation of DAn). Note that by $\mathrm{d} 4$ of differentiation $\mathrm{TH}^{+}$neurons are starting to appear in the cultures $(\approx 1-2 \%$ in the case of control hVM1 cells [34], Fig. 1C).

DAn generated from hVM1 hNSCs produce and release DA after depolarization [34-36], both in the presence and absence of elevated Bcl- $\mathrm{X}_{\mathrm{L}}$ levels. For a $\mathrm{TH}^{+}$neuron to synthesize $\mathrm{DA}$, at least two other enzymes are needed, aromatic aminoacid de-carboxylase (AADC), and GTP-Cyclohydrolase I (GTPCH, needed for the synthesis of the TH cofactor tetra-hydro-biopterin $\left.\left(\mathrm{BH}_{4}\right)\right)$. As shown in Supplementary information Fig. 3 both genes are expressed in control and $\mathrm{Bcl}-\mathrm{X}_{\mathrm{L}}$ cells. Their expression levels increased during the first week of differentiation in control hVM1 cells, whereas AADC increased and GTPCH remained nearly constant for Bcl- $\mathrm{X}_{\mathrm{L}}$ cells (Supplementary information Fig. $3 \mathrm{~A}$ ). When the expression data for these two genes were referred to those of TH (Supplementary information Fig. 3B) we found that their expression levels were significantly higher in $\mathrm{Bcl}-\mathrm{X}_{\mathrm{L}}$ cells when compared to control hVM1 ones, suggestive of an increased dopaminergic phenotype of the latter (for a given $\mathrm{TH}$ level). The expression of Dopamine- $\beta$-hydroxylase (DBH), which converts DA further into noradrenaline and adrenaline, present in $\mathrm{TH}^{+}$adrenergic neurons, was not detected by Q-PCR even after 40 cycles of amplification.

\section{Long term differentiation and expression of maturation, function-related genes}

As shown in Fig. 1, the number of neurons and $\mathrm{TH}^{+}$neurons does not increase with differentiation time beyond $\mathrm{d} 12$ of differentiation. To
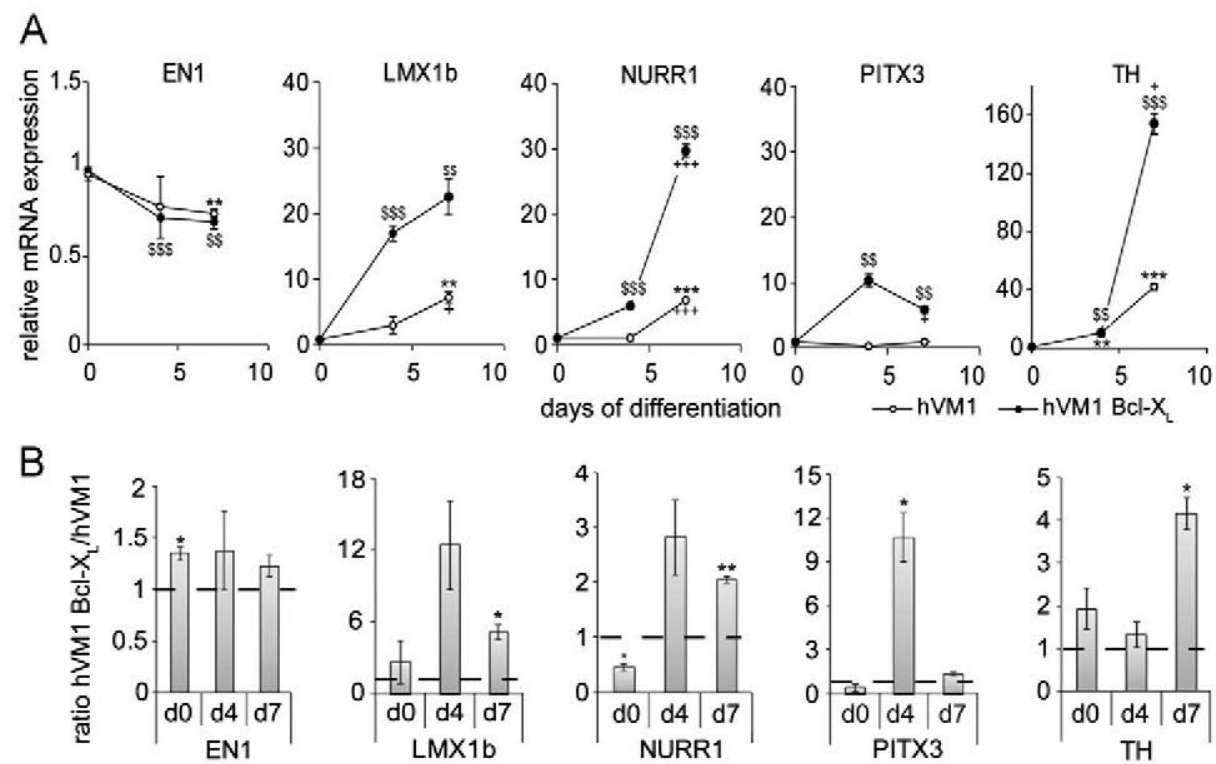

Fig. 3 - Expression of pro-dopaminergic genes during early differentiation times. (A) Relative mRNA temporal expression profile of EN1, LMX1b, NURR1, PITX3 and TH during one week of differentiation. Results are mean \pm SEM $(n=3)\left({ }^{* *} p<0.01,{ }^{* * *} p<0.001\right.$ vs hVM1 d0; $\$ p<0.01, \$ \beta<0.001$ vs hVM1 Bcl- $\mathrm{X}_{\mathrm{L}} \mathrm{d0} ;+\boldsymbol{p}<0.05,++p<0.001 \mathrm{~d} 4$ vs d7; $t$-test). (B) Bcl- $\mathrm{X}_{\mathrm{L}}$ effects on relative mRNA levels of the studied genes expressed as ratio hVM1 Bcl- $X_{L} / h V M 1$ at day 0,4 and 7 of differentiation. Results are mean \pm SEM $(n=3)\left({ }^{*} p<0.05,{ }^{* *} p<0.01\right.$, indicate that the mean differ significantly from 1 (equal values, $95 \%$ confidence interval); one sample $t$-test). 
study the maturation of the DAn long-term (up to d30), we selected four genes that must be co-expressed with $\mathrm{TH}$ in a functional DAn: dopamine transporter (DAT), vesicular monoamine transporter 2 (VMAT2), dopamine receptor subtype 2 (DRD2), and the G-protein coupled inwardly rectifying $\mathrm{K}$ channel (GIRK2, almost exclusive of A9-DAn).

(A) Temporal profile: TH mRNA levels peaked at $\mathrm{d} 12$ in control cells, decreasing afterwards (Fig. 4Ai), in parallel to $\mathrm{TH}^{+}$ neurons (Fig. 1C); opposite, the four function-related genes continued increasing their expression during the month studied (Fig. 4B). This points to a long differentiation time required by $\mathrm{TH}^{+}$neurons to become functionally active (as proposed in $[26,40,48])$. In the case of $\mathrm{Bcl}-\mathrm{X}_{\mathrm{L}}$ cells, the time course of expression was notoriously different, since DAT, VMAT and DRD2 expression peaked at d12 instead of d30 (Fig. 4B). This might be suggestive of the DAn maturing faster in the presence of elevated levels of $\mathrm{Bcl}-\mathrm{X}_{\mathrm{L}}$.

(B) Net Bcl- $X_{L}$ effects on gene expression: TH expression was enhanced 2-fold in Bcl- $\mathrm{X}_{\mathrm{L}}$ cells by $\mathrm{d} 30$ (Fig. 4Aii), in parallel to $\mathrm{TH}^{+}$neurons (Fig. 1C). For DAT, VMAT2, DRD2 and GIRK2, the ratio of expression in the presence or absence of increased $\mathrm{Bcl}-\mathrm{X}_{\mathrm{L}}$ levels (data treated as in Fig. $2 \mathrm{~B}$ and Fig. 3B, ratio $\mathrm{Bcl}-\mathrm{X}_{\mathrm{L}}$ to control cells) did not reveal any relevant changes (results not shown). When expression data of the four genes in each cell line were normalized to TH levels (an indication of their DA phenotype), we found that $\mathrm{Bcl}-\mathrm{X}_{\mathrm{L}}$ did not make the neurons more mature per unit of TH expression (Fig. 4C), but prevents the decrease in expression of these genes observed in control cells by d30. Similar results were obtained after WB or ICC determinations shown in Fig. 4D and E, showing that by $\mathrm{d} 30$ there is more $\mathrm{TH}$ protein or cells in the case of $\mathrm{Bcl}-\mathrm{X}_{\mathrm{L}}$ cultures, an enhancement that is accompanied by the increased presence of the other four proteins.

\section{Long-term expression of transcription factors required for function and survival}

Recent studies have proposed a maintenance and survival role for some of the factors studied here (EN1, LMX1B, NURR1 and PITX3), in addition to their known developmental roles [49-55] (reviewed in $[6,15,49]$ ). We therefore analyzed their expression in 30d-differentiated control and Bcl- $X_{L}$ hVM1 cells. When referring expression data to the level at $\mathrm{d} 0$, in control cells, NURR1 was the only gene expressed long term at slightly higher levels than in non-differentiated cells, whilst EN1 and LMX1B expression returned to basal levels (Fig. 5A) (PITX3 never got activated, see Fig. 3). In sharp contrast, the forced expression of $\mathrm{Bcl}-\mathrm{X}_{\mathrm{L}}$ yields cultures where most genes were expressed longterm at higher levels than in dividing cells (10-40 fold enhancement) (EN1 is slightly below levels seen at d0, 0.86 -fold) (Fig. 5A). The net fold enhancement of transcription levels induced by Bcl- $\mathrm{X}_{\mathrm{L}}$ (Fig. 5B) was $20-50$ folds for LMX1B, NURR1 and PTTX3, and 1.42-fold for EN1. This enhancement cannot be attributed solely to a survival action of $\mathrm{Bcl}-\mathrm{X}_{\mathrm{L}}$ since $\mathrm{TH}^{+}$neurons only increased 2 -fold (Fig. 1C).

\section{Morphological and functional long-term maturation of the DAn}

A detailed morphometric account of the shape and arborization of the $\mathrm{TH}^{+}$neurons after differentiation oh hVM1 cells, and of $\mathrm{Bcl}-\mathrm{X}_{\mathrm{L}}$ effects on these parameters, has not been previously undertaken. To this end, we differentiated the cultures for one month (plus/minus forced expression of $\mathrm{Bcl}-\mathrm{X}_{\mathrm{L}}$ ), and studied their evolution. To challenge the human system, we used as a control the best possible counterpart, a primary neuronal culture derived from fetal mouse VM. The results in terms of soma size, and the type, number and length of neurites present in the $\mathrm{TH}^{+}$ neurons are summarized in Fig. 6. Similarly to primary neurons, in control and Bcl- $X_{\mathrm{L}}$ hVM1 cells we found mid size neurons with ovoid, polygonal or fusiform morphology, typical of A9-DAn. Neurons were bi- or multi-polar, and the mean soma area was not different between primary neurons and those derived from control or Bcl- $\mathrm{X}_{\mathrm{L}}$ hVM1 cells (Fig. 6A and B). Details of all parameters studied for each cell type, times of differentiation and neurite order are provided in Supplementary information Fig. 4. The number of each type of neurite (Fig. 6C) and their average length (Fig. 6D) at d30 of differentiation, overall show that the neurite number seem to be lower in the order primary culture $>\mathrm{hVM} 1>\mathrm{hVM} 1-\mathrm{Bcl}-\mathrm{X}_{\mathrm{L}}$, whereas neurite length gets compensated showing values that increase in the order $\mathrm{hVM} 1-\mathrm{Bcl}-\mathrm{X}_{\mathrm{L}}>\mathrm{hVM} 1>$ primary cultures. One may then conclude that the degree of arborization (Fig. $6 \mathrm{E}$ ) is rather similar between primary and hVM1 derived $\mathrm{TH}^{+}$neurons, the most noticeable difference being a reduction at $\mathrm{d} 30$ to approximately one half in $\mathrm{Bcl}-\mathrm{X}_{\mathrm{L}}$ derived neurons.

Control hVM1 cells differentiate into functional neurons, according to calcium handling and electrophysiological parameters [40]. Since electrophysiological properties of SNpc are well established, here we only studied differentiated cultures of Bcl- $X_{L}$ hVM1 cells. Twenty-six of forty-nine cells that were analyzed electrophysiological displayed early neuronal properties, including broad, relatively immature action potentials that where blocked by the sodium channel blocker TTX, and rectification of membrane currents (Fig. 7A and B). Electrophysiological evaluation, at d4 to d13 of differentiation, did not reveal any changes over time in input resistance $\left(R_{i}\right)$ or resting membrane potential (RMP), though some tendency for an increase of RMP was apparent (Fig. 7C and D). The overall RMP average for the whole population of neurons over all time points was $-48.2 \mathrm{mV}$ and the $R_{i}$ was $1404 \pm 188 \mathrm{M} \Omega$. The remaining population of the recorded cells ( 23 cells) displayed passive membrane properties and a lower $R_{i}$ at $111 \pm 12.6 \mathrm{M} \Omega$ and was considered as of a glial identity (Fig. 7E). The differences in membrane resistance and lack of presence of membrane rectifying properties allowed for very clear discrimination between neuronal and non-neuronal cell populations (Fig. 7F).

In summary, both control [40] and Bcl- $\mathrm{X}_{\mathrm{L}} \mathrm{hVM} 1$ cells (present work) differentiate in vitro exhibiting electrophysiological properties indicative of both neuronal and glial phenotypes. Electrophysiological neuronal characteristics of both cell lines indicate that DAn neurons that are part of the neuronal population show immature action potential, relatively depolarized resting membrane potential, and properties typical of A9 DAn like high input resistance $(2000 \mathrm{M} \Omega)$, and broad, low amplitude action potentials. Slow electrophysiological maturation, requiring up to 6 

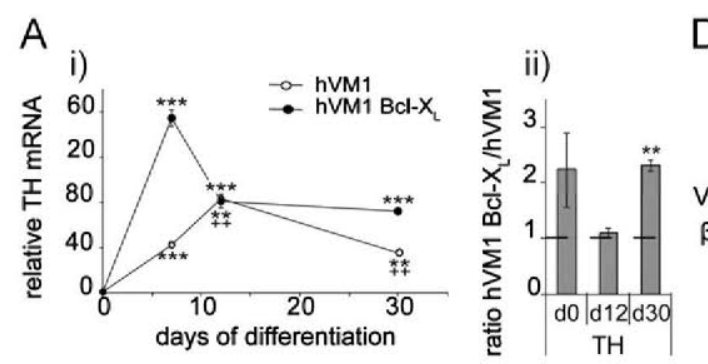

D
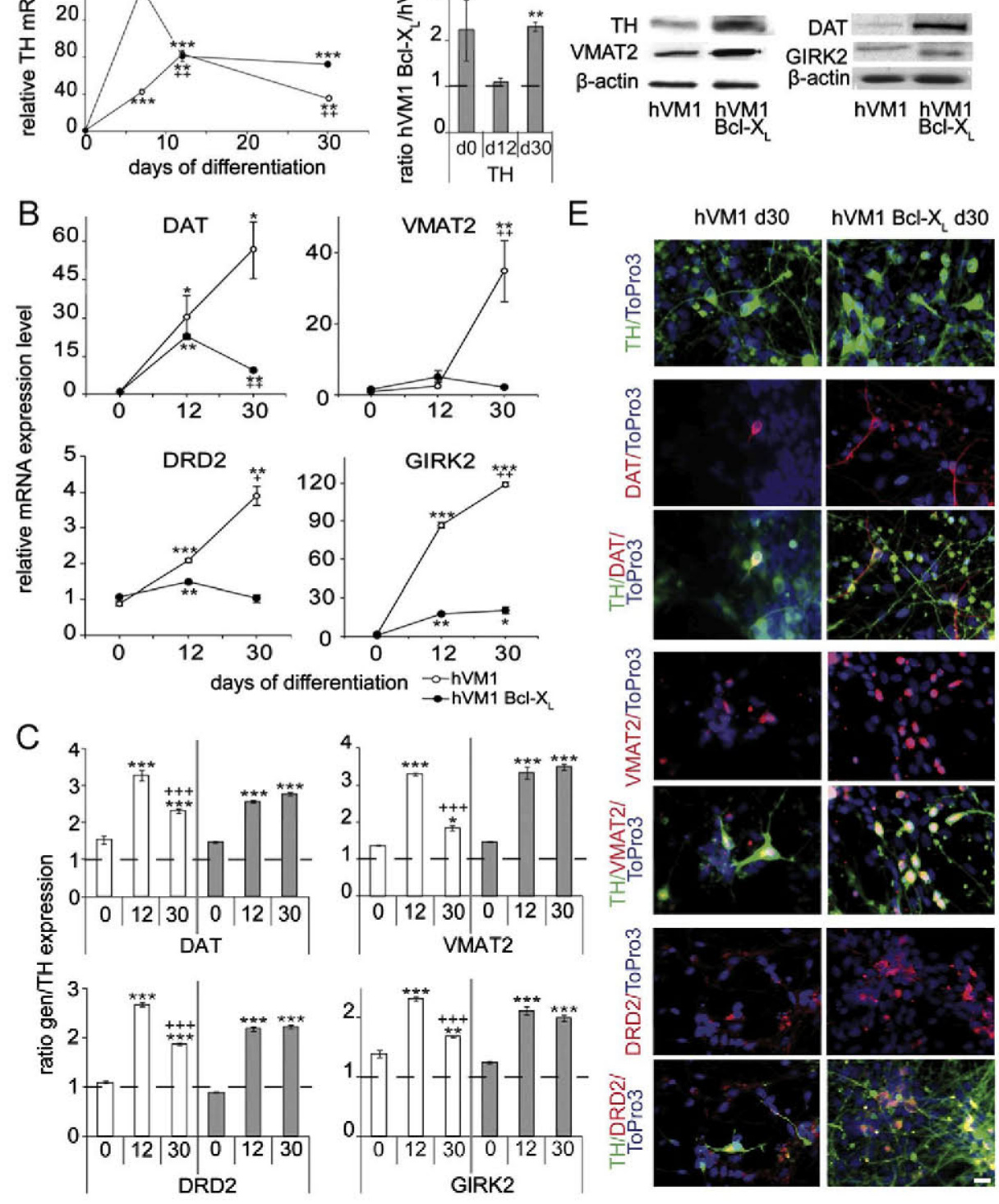

$\square \mathrm{hVM} 1 \quad \square \mathrm{hVM} 1 \mathrm{Bcl}-\mathrm{X}$

Fig. 4 - Expression studies of genes related with functional maturation of DAn. (A) TH expression during long-term differentiation. (Ai) Temporal TH mRNA expression profile determined by Q-RT-PCR. Data from each cell line was normalized to its own calibrator sample (value at day0, set as value 1; for further details see the Materials and methods section, and the legend for Supplementary Fig. S1). Results are mean $\pm \operatorname{SEM}(n=3)\left({ }^{* *} p<0.01,{ }^{* * *} p<0.001\right.$ vs d0; $+p<0.01$ vs previous day; $t$-test). (Aii) Bcl- $\mathrm{X}_{\mathrm{L}}$ effects on TH relative mRNA levels expressed as the ratio hVM1 Bcl- $\mathrm{X}_{\mathrm{L}} / \mathrm{hVM1}$ at each studied time. Results are mean \pm SEM $(n=3)\left({ }^{* *} p<0.01\right.$ indicates significantly from 1 (95\% confidence interval), one sample $t$ test). (B) Temporal DAT, VMAT2, DRD2 and GIRK2 mRNA expression profile determined by Q-RT-PCR at d0, d12 and d30 of differentiation. Results are mean \pm SEM $(\mathbf{n}=3)\left({ }^{* *} \boldsymbol{p}<0.01,{ }^{* * *} \boldsymbol{p}<0.001\right.$ vs $\mathrm{d0} ;+\boldsymbol{p}<0.05,++\boldsymbol{p}<0.01$ vs previous day; $\boldsymbol{t}$-test). (C) Comparative expression level of genes related to dopaminergic system $v s$ TH relative expression determined by ratio calculations (see Supp. Inf. Figs. 1 and 3 for more details). Results are mean \pm SEM $(n=3)\left({ }^{*} p<0.05,{ }^{* *} p<0.01,{ }^{* * *} p<0.001\right.$ indicate that the mean differs significantly from 1 (95\% confidence interval), one sample $t$-test); $++p<0.001 \mathrm{~d} 12$ vs $\mathrm{d} 30$ ( $t$-test). (D) Protein expression studies by immunoblots. The WBs show TH, VMAT2, DAT and GIRK2 protein levels in hVM1 and hVM1 Bcl- $\mathrm{X}_{\mathrm{L}}$ cells differentiated for 30 day. $\beta$-actin was used as loading control. (E) hVM1 and hVM1 Bcl- $X_{L}$ were analyzed by ICC at d30 of differentiation, detecting expression of TH, DAT, VMAT2 and DRD2 (red). These proteins colocalize with $\mathrm{TH}^{+}$cells (green). Nuclei were counterstained using ToPro3 (blue) (scale bar $=20 \mu \mathrm{m}$ ). (For interpretation of the references to color in this figure legend, the reader is referred to the web version of this article.) 
A

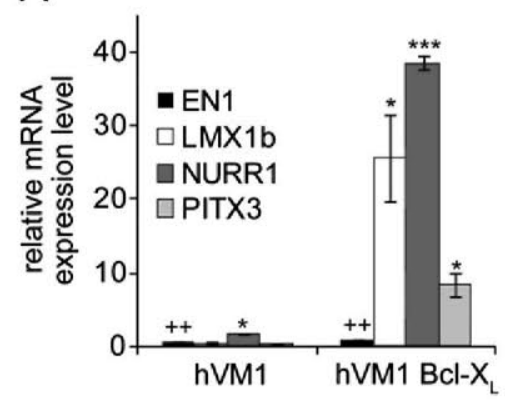

$\mathrm{B}$

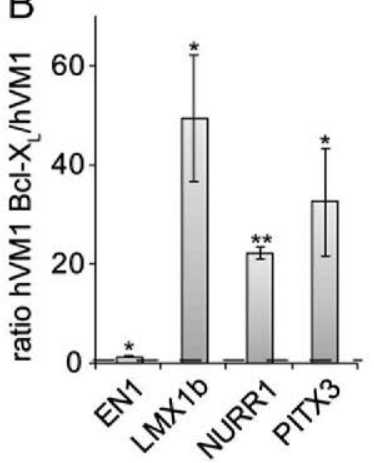

Fig. 5 - Long term expression of dopaminergic transcription factors involved in maintenance and survival. (A) Relative mRNA expression level of EN1, LMX1b, NURR1 and PITX3, at d30 of differentiation. Results are mean \pm SEM $(n=3)\left({ }^{*} p<0.05,{ }^{* * *} p<0.001\right.$ indicate higher expression than at $\mathbf{d 0} ;++p<0.01$ indicates lower expression than at d0; $t$-test). (B) Comparative expression level of dopaminergic transcription factors in hVM1 $\mathrm{Bcl}_{\mathrm{L}} \mathrm{X}_{\mathrm{L}}$ vs $\mathrm{hVM1}$ determined by ratio calculations at d30 of differentiation. Results are mean \pm SEM $(n=3)\left({ }^{*} p<0.05,{ }^{* *} p<0.01\right.$ indicate a significant difference from value 1 (95\% confidence interval), one sample $t$ test).

weeks of differentiation, has also been reported for human telencephalic precursor-derived neurons in vitro [56].

Another functional property of interest is the ability of the differentiated cultures for DA uptake, mediated by functional DAT. Positive evidence for a functional DA transport not only adds on the functionality of the neurons, but also comes to validate the Q-RT-PCR data shown in previous sections (Fig. 4). First, we studied ASP transport and accumulation (Fig. 8A), what indicated a clear NMF-sensitive accumulation in primary cultures, and in control and $\mathrm{Bcl}-\mathrm{X}_{\mathrm{L}}$ hVM1 differentiated cultures. Second, we studied the NMF-sensitive 6-OHDA-induced $\mathrm{TH}^{+}$ neuronal death (Fig. 8B) finding that 6-OHDA kills a substantial fraction of the $\mathrm{TH}^{+}$neurons generated in these cultures, but not in the presence of NMF, meaning that it was induced by toxin accumulation via DAT-mediated transport (and not by unspecific 6-OHDA toxicity caused by auto-oxidation). And thirdly, we measured the actual transport of $\left[{ }^{3} \mathrm{H}\right]-\mathrm{DA}$, finding no differences in the NMF-sensitive transport per $\mathrm{TH}^{+}$cell in the three types of cultures (Fig. 8C). In conclusion, from the point of view of the presence and activity of a functional DAT, there are no differences between the DAn generated by a primary fetal neuronal culture and those generated by control or Bcl- $\mathrm{X}_{\mathrm{L}} \mathrm{hVM} 1$ cells.

\section{Discussion}

When large numbers of identical neurons are required, as for drug testing or to complete a clinical trial, a continuous and stable source of genuine A9-DAn is needed. The present scenario is challenging since the capacity of human fetal VM precursor cultures to generate A9-DAn is controversial $[8,28,29]$. Human VM neurospheres show a limited expansion capacity, cease to yield DAn (and neurons) with passaging in culture, and in some cases the few DAn present are not born in culture [26,57-59], phenomena also described in rodents $[25,60,61]$. Adherent human VM FP radial glia cultures cells have been described to maintain their neurogenic potential, but do not differentiate into DAn [20]. Therefore, effort has been put on interventions aimed at enhancing neuron generation $[26,58,62]$. In the end, there exists the uncertainty of whether or not patterned precursors for human A9-DAn can be propagated in culture while retaining proper cell intrinsic information. In parallel to the work with primary cultures, several groups have developed immortalized hNSC lines derived from the fetal human VM (MESC2.10, NGC-407, ReNcell VM, vm c-mycER ${ }^{\mathrm{TM}}$ and hVM1, Refs. [30-34]). However, their properties and capacity to activate correct developmental programs, has remained largely unexplored or uncertain. In most cases only nestin and $\mathrm{TH}$ expression have been reported.

\section{Regionalization and activation of developmental gene cascades in hVM1 precursor cells}

The proposition that regionally specified precursors can be propagated long-term in culture implies that the cells must retain their patterning, which is not granted. Patterning preservation has been demonstrated in cortical, striatal and midbrain neurospheres $[57,58,63]$, but there is only indirect evidence for FB or VM v-myc hNSC lines [34-36,40-42,64], and the cell lines have never been studied head-to-head. In the present work we first clarified that long-term cultured FB and VM hNSCs differentially express early neuroectodermal markers (PAX6, EN1), and generate neurons showing differential expression of A9-DAn genes (such as GIRK2) (Fig. 1A). In the mouse embryo, Pax6 is expressed in the neuroectoderm of the FB and hindbrain [64]. In human stem cells PAX6 acts as a determinant of neuroectoderm fate [65-67]. Consistently, some expression was detected in hVM1 cells, but it was higher in hNS1 cells (Fig. 1A). EN1, characteristic of the midbrain neuroepithelium, and TH, DAT and GIRK2 expression were substantially higher in hVM1 cells, as compared to hNS1 ones. OTX2, involved in the positioning of the midbrain/hindbrain boundary, maintenance of precursor domains, and precursor proliferation and maturation $[6,9,17,45,68]$ was also expressed in hVM1 cells (Supplementary information Fig. 1). Altogether, these data not only indicate the persistence of a developmental program and patterning preservation, but also identify the hVM1 cells as neural stem cells showing most features of FP VM precursors for A9-DAn (expression of midbrain developmental genes (EN1, OTX2), neuroepithelial genes (SOX2), early midbrain and dopaminergic genes such 

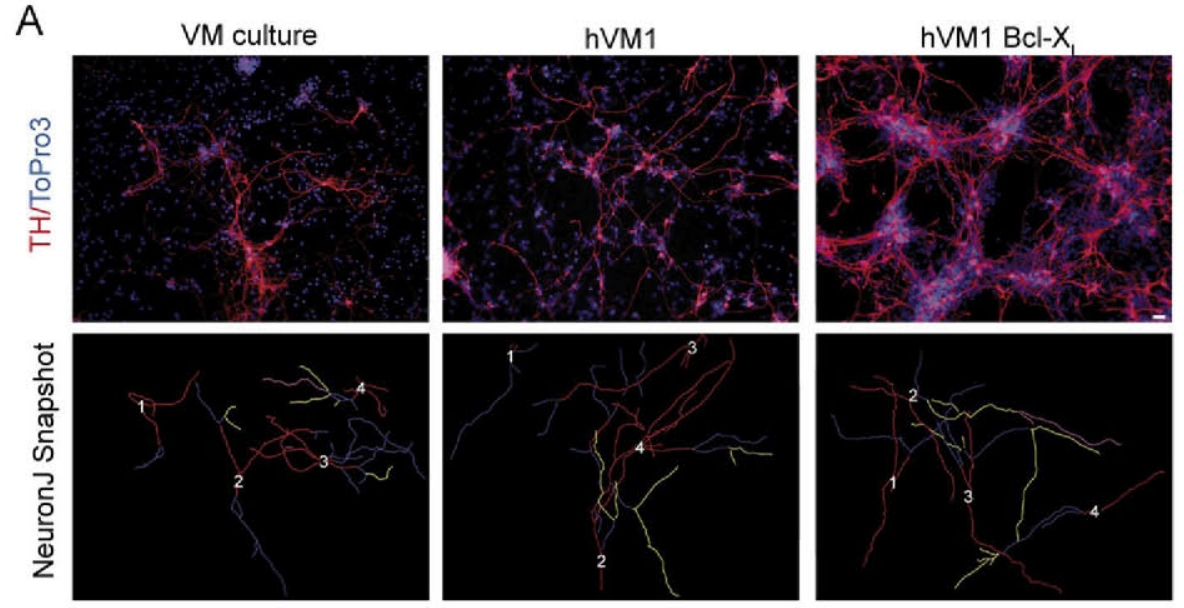

— primary — secondary — tertiary — quaternary

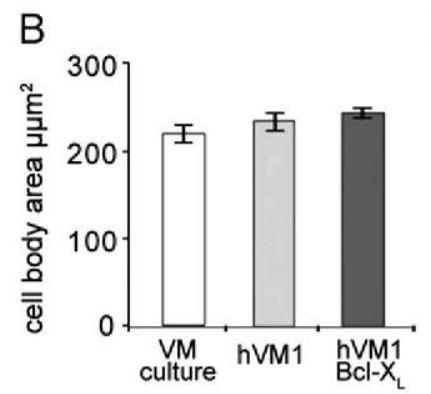

E
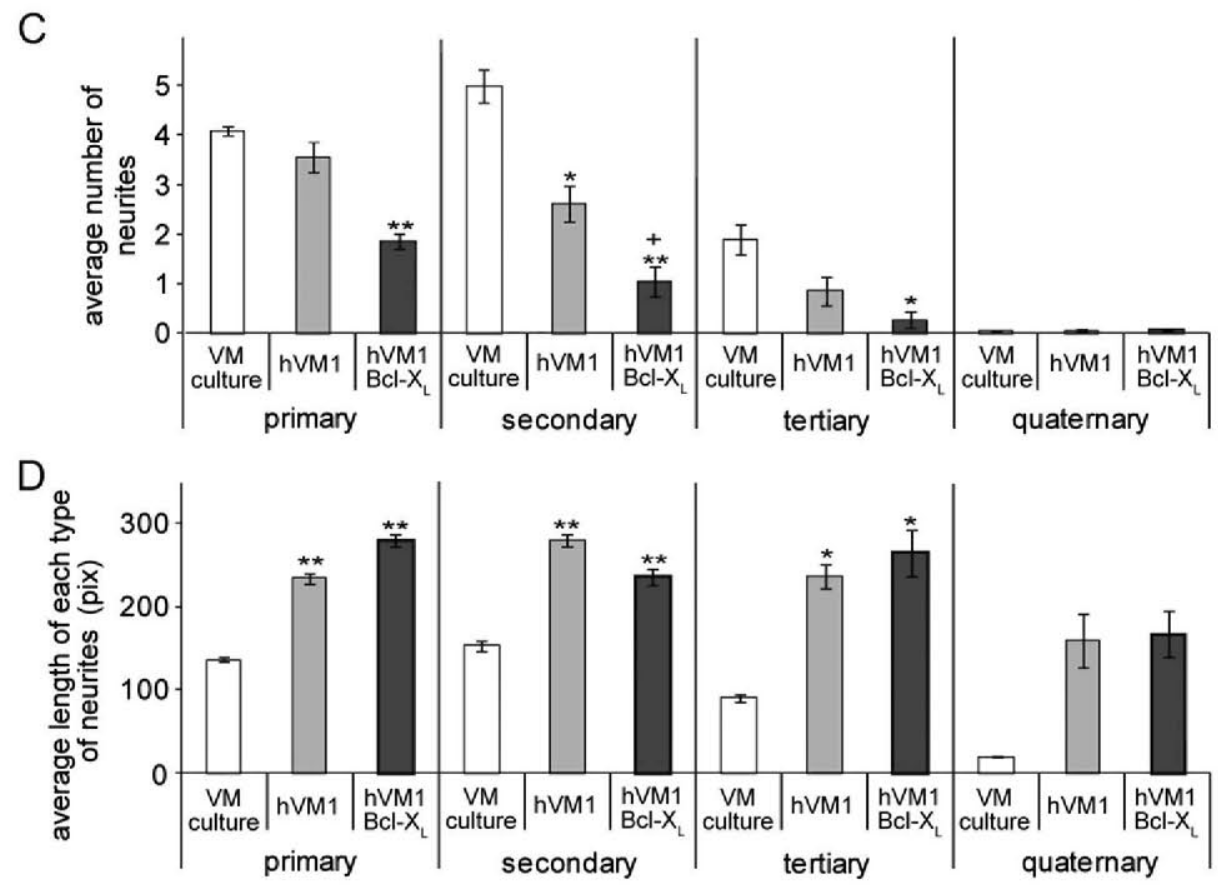

Fig. 6 - Morphometric analysis of dopaminergic neurons. Measurement of different parameters of $\mathrm{TH}^{+}$cells in primary fetal (E12) mouse VM cultures, hVM1 and hVM1 Bcl- $X_{L}$ cells after long-term differentiation. hVM1 and hVM1 Bcl- $X_{L}$ were differentiated for 30 day, and VM control cultures were maintained 22 day in vitro. (A) ICC for TH (red) and nuclear stain (blue, ToPro3). Snapshots taken with NeuronJ plug-in show semi-automatically traced neurites in different colors (see legend) in four analyzed neurons per picture (scale bar $=40 \mu \mathrm{m}$ ). (B) Cell body area was calculated by ImageJ and expressed as mean \pm SEM ( $n \geq 10$, ANOVA, post-hoc Tukey test). (C) Average number of each neurite type per $\mathrm{TH}^{+}$cells. Results were expressed as mean \pm SEM $(n \geq 50)$, $\left({ }^{*} p<0.05\right.$, ${ }^{* *} \boldsymbol{p}<0.01$ vs VM culture; $+\boldsymbol{p}<0.05 \mathrm{hVM1}$ vs hVM1 Bcl- $\mathrm{X}_{\mathrm{L}}$ cells; Kruskal Wallis test). (D) Average length of each type of neurites present in $\mathrm{TH}^{+}$cells expressed as mean \pm SEM $(n \geq 50),\left({ }^{*} p<0.05,{ }^{* *} p<0.01\right.$ indicate significant differences with VM culture; Kruskal Wallis test). (E) Total arborization (neurite length). Results are expressed as mean \pm SEM $(\boldsymbol{n} \geq \mathbf{5 0}),\left({ }^{*} \boldsymbol{p}<0.05,{ }^{* * *} \boldsymbol{p}<0.001\right.$ vs d12; $+p<0.05,+p<0.01,++p<0.001$ vs VM culture at each day; ${ }^{\circ \circ} p<0.001$ hVM1 vs hVM1 Bcl- $\mathrm{X}_{\mathrm{L}}$ at each day; ANOVA, posthoc Tukey test). 
A

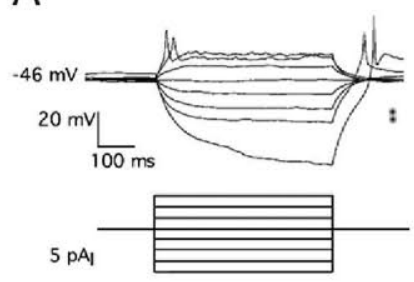

B

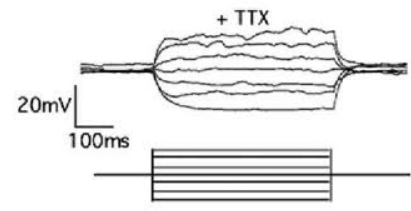

C

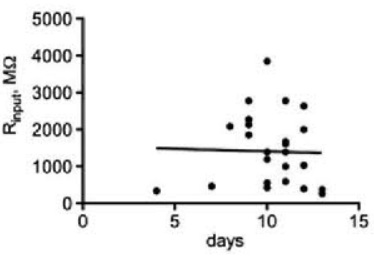

D

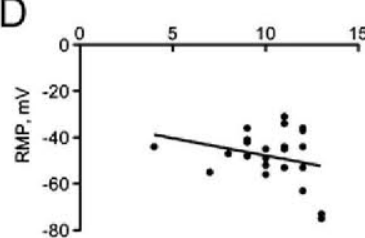

$\mathrm{E}$

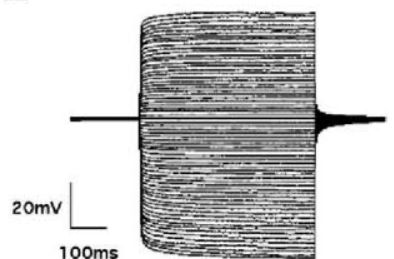

$\mathrm{F}$

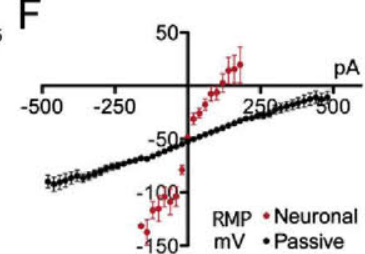

Fig. 7 - Electrophysiological properties of differentiated hVM1 Bcl- $X_{L}$ cells. (A) Twenty-six of 49 recorded cells were characterized as neuronal based on rectification of the membrane voltage in response to stepwise current injections and on firing of immature action potentials in response to current injections. (B) Immature action potentials were blocked in the presence of the sodium channel blocker TTX. (C) The input resistance of recorded neuronal cells did not change over the measuring period. (D) A tendency for an increase in the membrane potential could be observed among the neuronal cells during the measuring period, though this did not reach significance. (E) Example of voltage response of passive cell classified as non-neuronal. No rectification or active membrane properties can be observed in response to positive and negative current injection steps at $20 \mathrm{pA}$ increments. (F) Current/voltage curves of the neuronal and the passive cell populations, illustrated as the resting membrane potential (RMP) dependency on current injections. The different membrane properties of the neuronal and noneuronal, passive population are evident from the differing responses to current injections.

as LMX1A, LMX1B, NGN2, MASH1, PITX3, together with the expression of nestin, vimentin, and radial glia markers (such as 3CB2)). The expression of functional properties typical of A9-DAn in the progeny of hVM1 cells further substantiates this view (present work and [34-36]). Moreover, among calcium binding proteins, only calretinin is expressed in $\mathrm{TH}^{+}$neurons, but not calbindin or parvalbumin typical of ventral tegmental areas DAn (E.G.Seiz unpublished). Regarding developmental stages, to consider the hVM1 cells as VM DAn precursors is not in conflict with the gestational age of the fetus from which they were derived (10 weeks post conception (PC) [34]). This age is roughly equivalent to E14 in mice, a time when TH neurogenesis is considered over [69]. However, seminal studies indicate that, in humans, neurogenesis is protracted in time, peaking during PC weeks 6.5 to 8 and finishing by PC week $10-11$, a stage where newborn $\mathrm{TH}^{+}$ neurons are still present in the ventricular zone and have not yet migrated to the mantle zone [70]. Furthermore, VM dopamine content in human embryos continuously increases well beyond PC week 10 [71].

When mitogens are withdrawn the cells start to differentiate, and the percentage of nestin or Ki-67 positive cells quickly decreases to $20-30 \%$ by one-two weeks (Supplementary information Fig. 2), matching what has been described for FB-derived hNS1 cells $[42,72]$, and human cortical, striatal and VM neurosphere cultures $[26,63]$. Nestin ${ }^{+}$cells only disappeared completely by d30, enforcing the view that hNSCs require long differentiation times in vitro to mature (present work and see also $[26,40,63]$ ). The forced expression of $\mathrm{Bcl}-\mathrm{X}_{\mathrm{L}}$ did not alter the down-regulation of these markers (Supplementary information Fig. 2).

For neurogenesis to take place a set of proneural genes must be activated early during differentiation. Here we have studied MASH1, NGN2 and MSX1, essential for VM DAn generation (NEUROD1 was studied in Ref. [34]). MASH1 cooperates in a permissive manner in the generation of VM DAn, both in rodents and humans $[23,27,46,47]$. MSX1 prevents alternative cell fates through the repression of $N k x 6.1$ and activates $N g n 2$ expression $[6,24,43,45]$. In the case of the human brain, there is no information in the literature about MSX1 expression, but for the lack of effect of its over-expression in the NGC-407 cell line of human VM precursors. However, in this cell line, endogenous levels of MSX1 were not studied [61]. NGN2 is essential for the conversion of Otx $2^{+}$precursors into Nurr $1^{+}$postmitotic DAn, and its ablation dramatically reduces VM DAn numbers $[6,17,18,44,46,68]$. For the case of MASH1 and NGN2 we have reproduced previous data $[34,36]$ which, together with the data on MSX1 (Fig. 2), indicate that these proneural genes are expressed in hVM1 cells, following the expected time course, being MSX1 and NGN2 transiently activated. As discussed below, the forced expression of $\mathrm{Bcl}-\mathrm{X}_{\mathrm{L}}$ profoundly alters the expression of MSX1 and NGN2.

\section{Activation of developmental pro-dopaminergic genes}

Regionally specified (EN1, OTX2) and neuron committed (MASH1, MSX1 and NGN2) precursors (Figs. 1 and 2) must activate genes required for the development of a correct A9-DA phenotype, at a time in the mouse when the cells exit the cell cycle [21,22]. Nurr1 expression in the mouse (cooperating with Pitx3) is critical for the acquisition of the correct DA phenotype (that requires co-expression of TH, AADC, VMAT2 and DAT) $[17,22,73,74]$. In relation to LMX1B, loss of function studies indicate that is required for the maintenance of VM DAn [75], and more recently it has been involved in patterning $[12,18,76]$. hVM1 cells activate NURR1 and LMX1B during the first week of differentiation (Fig. 3), in parallel to cell cycle exit (Supplementary information Fig. 2), and prior to the blow of TH expression, as temporally expected and normally occurs during mouse and human development. PITX3 expression, 
A

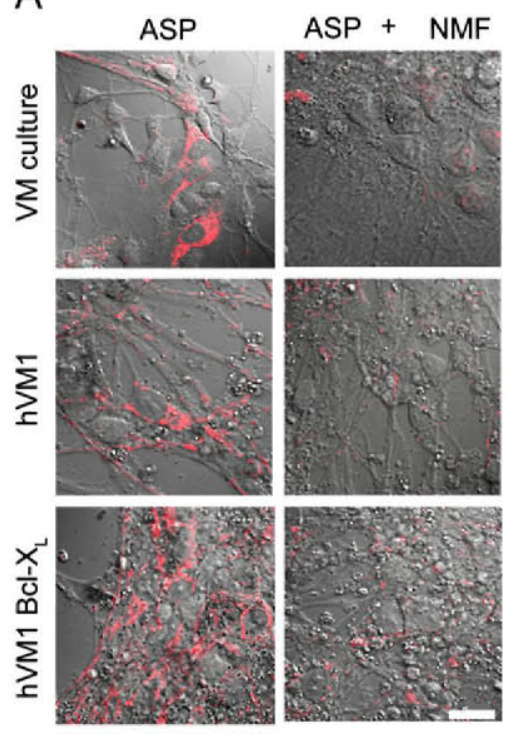

B
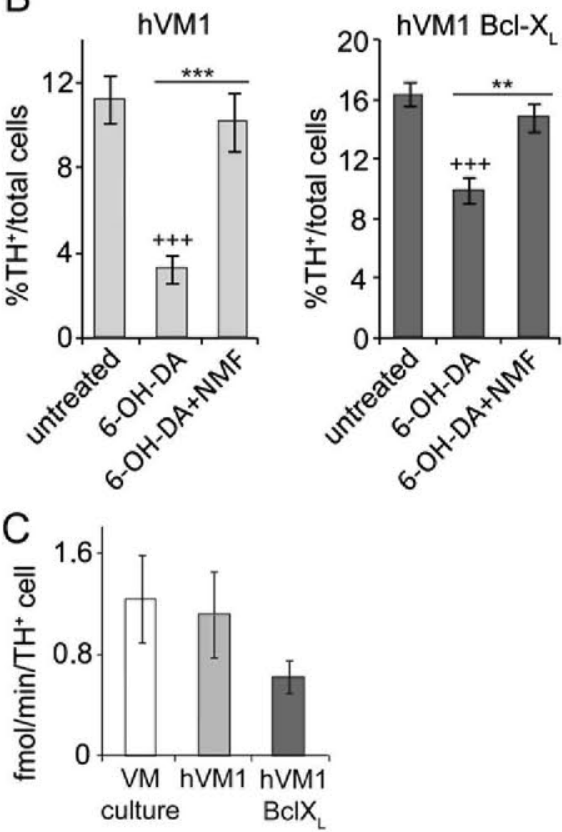

Fig. 8 - Dopamine transporter (DAT) activity in differentiated cells. (A) In vivo studies of DAT activity by ASP $^{+}$labeling in primary VM cultures (d7) and hVM1 and hVM1 Bcl- $\mathrm{X}_{\mathrm{L}}$ cells $(\mathrm{d} 30)$, in the presence or absence of NMF (10 $\left.\mu \mathrm{M}\right)$ to block DAT activity and visualize specific transport via DAT. Fluorescence confocal microscopy images were collected (scale bar $=20 \mu \mathrm{m}$ ). Cells with a functional DAT are seen in red. (B) Functional assay of DAT detected by 6-OH-DA -induced toxicity. hVM1 and hVM1 Bcl- $\mathrm{X}_{\mathrm{L}}$ cells (30d) were treated with 6-OHDA (50 mM) in the presence or absence of NMF for 2 day, and stained for TH. Each experiment was performed in triplicate and analyzed by one way ANOVA and Tukey's post hoc test $\left({ }^{* *} \boldsymbol{p}<0.01,{ }^{* * *} \boldsymbol{p}<0.001\right.$ 6-0HDA vs 6OHDA+NMF treated cultures; $++\boldsymbol{p}<0.001$ vs untreated cultures). (C) Direct functional assay of DAT activity by [ $\left.{ }^{3} \mathrm{H}\right]$ dopamine uptake. The data correspond to DAT-mediated specific transport, calculated by subtracting the non-specific uptake (determined in parallel NMF treated cultures). Results are expressed per single $\mathrm{TH}^{+}$cell, counted in sister, stained cultures. There are not significant differences between cultures. Results are mean \pm SEM ( $n=6)$ ANOVA, posthoc Tukey test).

however, did not activate, possibly explaining a lower-than-possible yield of DAn in control cells. The expression levels of LMX1B and NURR1, and most notably that of PITX3, are enhanced after forced $\mathrm{Bcl}-\mathrm{X}_{\mathrm{L}}$ expression (Fig. 3B), what may be of critical importance to enhance DAn generation (see the Discussion section).

\section{Maturation, function and maintenance of DAn}

Consistent with our previous reports showing that DAn from hVM1 cells can synthesize and release DA after depolarization [34-36], here we show that the genes needed for DA synthesis (TH, AADC and GTPCH1) are in fact expressed during differentiation (Figs. 1, 3 and 4, S3). The electrophysiological data (showing active neurons) we present here for differentiated Bcl- $\mathrm{X}_{\mathrm{L}} \mathrm{hVM} 1$ cells largely correspond to those previously reported for the control hVM1 cell line [40]. Though these neuronal electrophysiological properties seem to be relatively immature, it is possible that with longer differentiation times, or upon grafting, the cells may develop into more functionally mature neurons. This notion is partly supported by the observed tendency to an increase in membrane potential over time. Nevertheless, some of the properties exhibited by the cells (high input resistance, trains of action potentials, and long duration action potentials are typical of A9 SNpc DAn). In this context, Lepski et al. [78] have also reported that telencephalic human neural precursors require about six weeks of in vitro differentiation to complete their electrophysiological maturation.
In the present study we have also generated detailed data on the correct activation of genes essential for A9-DAn function (DAT, VMAT2, DRD2 and GIRK2, Fig. 4B), which gradually increased over the month of differentiation studied, again indicating a slow maturation. Furthermore, we studied DAT activity by three independent means, and consistently found that there is an active DA transport in the differentiated DAn (Fig. 7), not different from that in primary neurons. Morphologically, $\mathrm{TH}^{+}$neurons did not substantially differ from those in primary culture (Fig. 6). In summary, DAn generated from hVM1 precursors express all genes needed for an A9 type DAn to be functional, available data indicate a high degree of both morphological and functional maturation of the obtained DAn. Bcl- $\mathrm{X}_{\mathrm{L}}$ effects on maturation are marginal, as discussed later.

EN1, LMX1B, NURR1 and PITX3 are not only involved in development, but also in the survival/maintenance of functional A9-DAn ([50-54] reviewed in [6,15,24,49,77]). In control hVM1 cells the expression levels of these genes first increase during differentiation (but for PITX3), to later return to values close to basal levels (Fig. 3A and Fig. 5A). This may explain why the percentage of $\mathrm{TH}^{+}$neurons decreased from 12 to $11 \%$ (d7-d12), down to $8 \%$ (d30) (Fig. 1C). The lack of up-regulation of PITX3 may also contribute to this decline, since it is crucial for DAn maintenance $[6,22,49]$. In sum, these data would point to a compromised maintenance of the DAn in the long perspective, although their morphology does not differ from that of the $\mathrm{TH}^{+}$ 
cells in primary cultures (Fig. 6, S4) and they are still functional (Figs. 7 and 8, and Ref. [40]).

\section{Integration of Bcl- $\mathrm{X}_{\mathrm{L}}$ effects}

$\mathrm{Bcl}-\mathrm{X}_{\mathrm{L}}$ has been described to exert multiple functions in hNSCs, by molecular and cellular mechanisms involving apoptosis, changes in gene expression, control of cell cycle duration, and expansion of intermediate progenitors $[34,36] \mathrm{Bcl}-\mathrm{X}_{\mathrm{L}}$ has been shown to act in FB and VM hNSCs in a dose-response fashion, conclusion validated by interfering RNA studies (such as those in [78] ). In the case of $\mathrm{VM}, \mathrm{Bcl}-\mathrm{X}_{\mathrm{L}}$ enhances the survival of A9-DAn, both in vitro and in vivo $[35,36]$, and rescues the neurogenic potential of hVM1 cells lost with passaging [36]. Those studies focused on cell death counteraction (reduced LDH release, Annexin- $\mathrm{V}^{+}$or caspase- $3^{+}$cells, DNA fragmentation). DA synthesis was also enhanced, as expected by the increased number of $\mathrm{TH}^{+}$cells generated. In the present study we have conducted a detailed long-term study of gene expression changes to explain further the $\mathrm{Bcl}-\mathrm{X}_{\mathrm{L}}$-induced enhanced generation of DAn. Present data indicate that $\mathrm{Bcl}-\mathrm{X}_{\mathrm{L}}$ has a dramatic effect in MSX1 temporal expression, anticipating it, and increasing the net levels of MSX1 and NGN2, in comparison to control cells (Fig. 2, see also Ref. [36]. At later stages, NURR1 is also enhanced, but most importantly, PITX3 activation is rescued (Fig. 4). Altogether, these gene expression changes (plus a small, 3 -fold increase in OTX2 expression, Supplementary information Fig. 1), are sufficient to explain the enhanced number of $\mathrm{TH}^{+}$neurons generated and $\mathrm{TH}$ mRNA levels at all times studied (Figs. 1, 3 and 4). Note that by d7, TH mRNA levels increase by 4-fold (Fig. 3B, 4Aii), whereas the number of $\mathrm{TH}^{+}$cells is only doubled (Fig. 1C). This, together with the increase in the expression of AADC and GTPCH1 (Fig. S2B), would suggest an enhanced dopaminergic phenotype. However, one cannot affirm that the cells are more mature in the presence of elevated levels of $\mathrm{Bcl}-\mathrm{X}_{\mathrm{L}}$. Long-term data on expression of function-related genes (Fig. 4) only indicate that the cells might mature faster, and that by $\mathrm{d} 30 \mathrm{Bcl}-\mathrm{X}_{\mathrm{L}}$ prevents the loss of the DA phenotype that occurs in control cells (at least when the data are normalized to TH mRNA, Fig. 4C). In addition, electrophysiology (Fig. 7), DAT activity determinations (Fig. 8), and morphological data (Fig. 6) also indicate that $\mathrm{Bcl}-\mathrm{X}_{\mathrm{L}}$ does not accelerate functional maturation in vitro.

\section{Conclusion}

In the present work we provide evidence demonstrating that VM hNSCs with the capacity to generate functional A9 DAn can be propagated in culture (at the expense of $\mathrm{v}$-myc), while retaining their patterning. These precursors resume their developmental instructions during differentiation, offering a stable and reproducible source of functional DAn for basic developmental studies, but also applied research in the fields of drug screening and cell therapy. The forced expression of $\mathrm{Bcl}-\mathrm{X}_{\mathrm{L}}$ results in an increased yield of DAn from VM hNSCs via cell death counteraction [36], but also enhancing neuron generation and maintenance (present work).

\section{Acknowledgments}

We would like to acknowledge the excellent technical assistance of Ignacio Tardieu de Chorro, Marta González Mella and Beatriz Moreno Moreno, Dr. Elisa García-García (CBMSO) for fruitful discussions, Dr. Ricardo Ramos (Scientific Park, Madrid) for Q-RT-PCR determinations and Veronica Labrador (CBMSO) for confocal microscopy assistance. Dr. Isabel Liste was partially supported by the Ramón y Cajal programme. This work was supported by EU (NMP-SL-2008-214706 EXCELL), MCyT (SAF2004-03405), MICINN/MINECO (BIO2007-66807, PLE20090101 and SAF2010-17167), Carlos III Institute of Health grant RETICS TerCel (RD06/0010/0009) and La Caixa Foundation (BM05-22-0). This work was also supported by an institutional grant from Foundation Ramón Areces to the Center of Molecular Biology Severo Ochoa.

\section{Appendix A. Supporting information}

Supplementary data associated with this article can be found in the online version at http://dx.doi.org/10.1016/j.yexcr.2012.07.018.

\section{R E F E R E N C E S}

[1] T.M. Tzschentke, W.J. Schmidt, Functional relationship among medial prefrontal cortex, nucleus accumbens, and ventral tegmental area in locomotion and reward, Crit. Rev. Neurobiol. 14 (2000) 131-142

[2] C.W. Olanow, W.G. Tatton, Etiology and pathogenesis of Parkinson's disease, Annu. Rev. Neurosci. 22 (1999) 123-144.

[3] O. Lindvall, A. Bjorklund, Cell therapy in Parkinson's disease, NeuroRx 1 (2004) 382-393.

[4] O. Lindvall, Z. Kokaia, A. Martinez-Serrano, Stem cell therapy for human neurodegenerative disorders-how to make it work, Nat Med. 10 (2004) S42-S50 Suppl.

[5] J.P. Burbach, M.P. Smidt, Molecular programming of stem cells into mesodiencephalic dopaminergic neurons, Trends Neurosci. 29 (2006) 601-603.

[6] R. Orme, R.A. Fricker-Gates, M.A. Gates, Ontogeny of substantia nigra dopamine neurons, J. Neural. Transm. Suppl. (2009) 3-18.

[7] O. Lindvall, Z. Kokaia, Prospects of stem cell therapy for replacing dopamine neurons in Parkinson's disease, Trends Pharmacol. Sci. 30 (2009) 260-267.

[8] O. Lindvall, Z. Kokaia, Stem cells in human neurodegenerative disorders-time for clinical translation?, J. Clin. Invest. 120 (2010) 29-40.

[9] E. Puelles, A. Annino, F. Tuorto, A. Usiello, D. Acampora, T. Czerny, C. Brodski, S.L. Ang, W. Wurst, A. Simeone, Otx2 regulates the extent, identity and fate of neuronal progenitor domains in the ventral midbrain, Development 131 (2004) 2037-2048.

[10] Y. Ono, T. Nakatani, Y. Sakamoto, E. Mizuhara, Y. Minaki, M. Kumai, A. Hamaguchi, M. Nishimura, Y. Inoue, H. Hayashi, J. Takahashi, T. Imai, Differences in neurogenic potential in floor plate cells along an anteroposterior location: midbrain dopaminergic neurons originate from mesencephalic floor plate cells, Development 134 (2007) 3213-3225.

[11] A.L. Ferri, W. Lin, Y.E. Mavromatakis, J.C. Wang, H. Sasaki, J.A. Whitsett, S.L. Ang, Foxa1 and Foxa2 regulate multiple phases of midbrain dopaminergic neuron development in a dosagedependent manner, Development 134 (2007) 2761-2769. 
[12] T. Nakatani, M. Kumai, E. Mizuhara, Y. Minaki, Y. Ono, Lmx1a and Lmx1b cooperate with Foxa2 to coordinate the specification of dopaminergic neurons and control of floor plate cell differentiation in the developing mesencephalon, Dev. Biol. 339 (2010) 101-113.

[13] E. Gale, M. Li, Midbrain dopaminergic neuron fate specification: of mice and embryonic stem cells, Mol. Brain 1 (2008) 8 .

[14] E. Puelles, Genetic control of basal midbrain development, J. Neurosci. Res. 85 (2007) 3530-3534.

[15] K.N. Alavian, C. Scholz, H.H. Simon, Transcriptional regulation of mesencephalic dopaminergic neurons: the full circle of life and death, Mov. Disord. 23 (2008) 319-328.

[16] A. Abeliovich, R. Hammond, Midbrain dopamine neuron differentiation: factors and fates, Dev. Biol. 304 (2007) 447-454.

[17] M.P. Smidt, J.P. Burbach, How to make a mesodiencephalic dopaminergic neuron, Nat. Rev. Neurosci. 8 (2007) 21-32.

[18] S.L. Ang, Transcriptional control of midbrain dopaminergic neuron development, Development 133 (2006) 3499-3506.

[19] N. Prakash, W. Wurst, Genetic networks controlling the development of midbrain dopaminergic neurons, J. Physiol. 575 (2006) 403-410.

[20] N. Prakash, W. Wurst, Development of dopaminergic neurons in the mammalian brain, Cell Mol. Life Sci. 63 (2006) 187-206.

[21] S. Bonilla, A.C. Hall, L. Pinto, A. Attardo, M. Gotz, W.B. Huttner, E. Arenas, Identification of midbrain floor plate radial glia-like cells as dopaminergic progenitors, Glia 56 (2008) 809-820.

[22] J.B. Hebsgaard, J. Nelander, H. Sabelstrom, M.E. Jonsson, S. Stott, M. Parmar, Dopamine neuron precursors within the developing human mesencephalon show radial glial characteristics, Glia 57 (2009) 1648-1658.

[23] J. Nelander, J.B. Hebsgaard, M. Parmar, Organization of the human embryonic ventral mesencephalon, Gene. Exp. Patterns 9 (2009) 555-561.

[24] H.J. Kim, Stem cell potential in Parkinson's disease and molecular factors for the generation of dopamine neurons, Biochim. Biophys. Acta 1812 (2010) 1-11.

[25] S. Chung, B.S. Shin, M. Hwang, T. Lardaro, U.J. Kang, O. Isacson, K.S. Kim, Neural precursors derived from embryonic stem cells, but not those from fetal ventral mesencephalon, maintain the potential to differentiate into dopaminergic neurons after expansion in vitro, Stem. Cells 24 (2006) 1583-1593.

[26] J. Maciaczyk, I. Singec, D. Maciaczyk, G. Nikkhah, Combined use of BDNF, ascorbic acid, low oxygen, and prolonged differentiation time generates tyrosine hydroxylase-expressing neurons after long-term in vitro expansion of human fetal midbrain precursor cells, Exp. Neurol. 213 (2008) 354-362.

[27] H.J. Kim, M. Sugimori, M. Nakafuku, C.N. Svendsen, Control of neurogenesis and tyrosine hydroxylase expression in neural progenitor cells through bHLH proteins and Nurr1, Exp. Neurol. 203 (2007) 394-405.

[28] A. Martínez-Serrano, I. Liste, Recent progress and challenges for the use of stem cell derivatives in neuron replacement therapy for Parkinson's disease, Future Neurol. 5 (2010) 161-165.

[29] P. Brundin, R.A. Barker, M. Parmar, Neural grafting in Parkinson's disease problems and possibilities, Prog. Brain Res. 184 (2010) 265-294.

[30] J. Lotharius, S. Barg, P. Wiekop, C. Lundberg, H.K. Raymon, P. Brundin, Effect of mutant alpha-synuclein on dopamine homeostasis in a new human mesencephalic cell line, J. Biol. Chem. 277 (2002) 38884-38894.

[31] Z. Khan, M. Akhtar, T. Asklund, B. Juliusson, P.M. Almqvist, T.J. Ekstrom, HDAC inhibition amplifies gap junction communication in neural progenitors: potential for cell-mediated enzyme prodrug therapy, Exp. Cell Res. 313 (2007) 2958-2967.

[32] R. Donato, E.A. Miljan, S.J. Hines, S. Aouabdi, K. Pollock, S. Patel, F.A. Edwards, J.D. Sinden, Differential development of neuronal physiological responsiveness in two human neural stem cell lines, BMC Neurosci. 8 (2007) 36.
[33] E.A. Miljan, S.J. Hines, P. Pande, R.L. Corteling, C. Hicks, V. Zbarsky, M. Umachandran, P. Sowinski, S. Richardson, E. Tang, M. Wieruszew, S. Patel, P. Stroemer, J.D. Sinden, Implantation of c-mycER TAM immortalized human mesencephalic-derived clonal cell lines ameliorates behavior dysfunction in a rat model of Parkinson's disease, Stem. Cells Dev. 18 (2009) 307-319.

[34] A. Villa, I. Liste, E.T. Courtois, E.G. Seiz, M. Ramos, M. Meyer, B. Juliusson, P. Kusk, A. Martinez-Serrano, Generation and properties of a new human ventral mesencephalic neural stem cell line, Exp. Cell Res. 315 (2009) 1860-1874.

[35] C. Krabbe, E. Courtois, P. Jensen, J.R. Jorgensen, J. Zimmer, A. Martinez-Serrano, M. Meyer, Enhanced dopaminergic differentiation of human neural stem cells by synergistic effect of Bcl$\mathrm{xL}$ and reduced oxygen tension, J. Neurochem. 110 (2009) $1908-1920$.

[36] E.T. Courtois, C.G. Castillo, E.G. Seiz, M. Ramos, C. Bueno, I. Liste, A. Martinez-Serrano, $I n$ vitro and in vivo enhanced generation of human A9 dopamine neurons from neural stem cells by Bcl-XL, J. Biol. Chem. 285 (2010) 9881-9897.

[37] J.Y. Ko, H.S. Lee, C.H. Park, H.C. Koh, Y.S. Lee, S.H. Lee, Conditions for tumor-free and dopamine neuron-enriched grafts after transplanting human ES cell-derived neural precursor cells, Mol. Ther. 17 (2009) 1761-1770.

[38] J. Pruszak, L. Just, O. Isacson, G. Nikkhah, Isolation and culture of ventral mesencephalic precursor cells and dopaminergic neurons from rodent brains, Curr. Protoc. Stem. Cell Biol. 11 (2009) $1-21$.

[39] J. Popko, A. Fernandes, D. Brites, L.M. Lanier., Automated analysis of NeuronJ tracing data, Cytometry A 75 (2009) 371-376.

[40] J. Tonnesen, E.G. Seiz, M. Ramos, O. Lindvall, A. MartinezSerrano, M. Kokaia, Functional properties of the human ventral mesencephalic neural stem cell line hVM1, Exp. Neurol. 223 (2010) 653-656.

[41] I. Liste, E. Garcia-Garcia, A. Martinez-Serrano, The generation of dopaminergic neurons by human neural stem cells is enhanced by Bcl-XL, both in vitro and in vivo, J. Neurosci. 24 (2004) 10786-10795.

[42] I. Liste, E. Garcia-Garcia, C. Bueno, A. Martinez-Serrano, Bcl-XL modulates the differentiation of immortalized human neural stem cells, Cell Death Differ. 14 (2007) 1880-1892.

[43] E. Andersson, U. Tryggvason, Q. Deng, S. Friling, Z. Alekseenko, B. Robert, T. Perlmann, J. Ericson, Identification of intrinsic determinants of midbrain dopamine neurons, Cell 124 (2006) 393-405.

[44] E. Andersson, J.B. Jensen, M. Parmar, F. Guillemot, A. Bjorklund, Development of the mesencephalic dopaminergic neuron system is compromised in the absence of neurogenin 2, Development 133 (2006) 507-516.

[45] D. Omodei, D. Acampora, P. Mancuso, N. Prakash, L.G. Di Giovannantonio, W. Wurst, A. Simeone, Anterior-posterior graded response to Otx2 controls proliferation and differentiation of dopaminergic progenitors in the ventral mesencephalon, Development 135 (2008) 3459-3470.

[46] J. Kele, N. Simplicio, A.L. Ferri, H. Mira, F. Guillemot, E. Arenas, S.L. Ang, Neurogenin 2 is required for the development of ventral midbrain dopaminergic neurons, Development 133 (2006) 495-505.

[47] C.H. Park, J.S. Kang, J.S. Kim, S. Chung, J.Y. Koh, E.H. Yoon, A.Y. Jo, M.Y. Chang, H.C. Koh, S. Hwang, H. Suh-Kim, Y.S. Lee, K.S. Kim, S.H. Lee, Differential actions of the proneural genes encoding Mash1 and neurogenins in Nurr1-induced dopamine neuron differentiation, J. Cell Sci. 119 (2006) 2310-2320.

[48] P. Brundin, A. Bjorklund, Survival of expanded dopaminergic precursors is critical for clinical trials, Nat. Neurosci. 1 (1998) 537.

[49] J. Li, J.A. Dani, W. Le, The role of transcription factor Pitx3 in dopamine neuron development and Parkinson's disease, Curr. Top Med. Chem. 9 (2009) 855-859. 
[50] L. Sonnier, G. Le Pen, A. Hartmann, J.C. Bizot, F. Trovero, M.O. Krebs, A. Prochiantz, Progressive loss of dopaminergic neurons in the ventral midbrain of adult mice heterozygote for Engrailed1, J. Neurosci. 27 (2007) 1063-1071.

[51] P. Sgado, L. Alberi, D. Gherbassi, S.L. Galasso, G.M. Ramakers, K.N. Alavian, M.P. Smidt, R.H. Dyck, H.H. Simon, Slow progressive degeneration of nigral dopaminergic neurons in postnatal Engrailed mutant mice, Proc. Nat. Acad. Sci. U.S.A. 103 (2006) 15242-15247.

[52] P. Sgado, C. Viaggi, C. Fantacci, G.U. Corsini, Characterization of the Engrailed mutant mice as experimental models for Parkinson's disease, Parkinsonism Relat. Disord. 14 (2) (2008) S103-S106.

[53] B. Kadkhodaei, T. Ito, E. Joodmardi, B. Mattsson, C. Rouillard, M. Carta, S. Muramatsu, C. Sumi-Ichinose, T. Nomura, D. Metzger, P. Chambon, E. Lindqvist, N.G. Larsson, L. Olson, A. Bjorklund, H. Ichinose, T. Perlmann, Nurr1 is required for maintenance of maturing and adult midbrain dopamine neurons, J. Neurosci, 29 (2009) 15923-15932.

[54] T. Papanikolaou, T. Amano, J. Lennington, K. Sink, A.M. Farrar, J. Salamone, X. Yang, J.C. Conover, In-vitro analysis of Pitx3 in mesodiencephalic dopaminergic neuron maturation, Eur. J. Neurosci. 29 (2009) 2264-2275.

[55] F.M. Jacobs, S. van Erp, A.J. van der Linden, L. von Oerthel, J.P. Burbach, M.P. Smidt, Pitx3 potentiates Nurr1 in dopamine neuron terminal differentiation through release of SMRTmediated repression, Development 136 (2009) 531-540.

[56] G. Lepski, J. Maciaczyk, C.E. Jannes, D. Maciaczyk, J. Bischofberger, G. Nikkhah, Delayed functional maturation of human neuronal progenitor cells in vitro, Mol. Cell Neurosci. 47 (2011) 36-44.

[57] T. Ostenfeld, E. Joly, Y.T. Tai, A. Peters, M. Caldwell, E. Jauniaux, C.N. Svendsen, Regional specification of rodent and human neurospheres, Brain Res. Dev. Brain Res. 134 (2002) 43-55.

[58] H.J. Kim, E. MclMillan, F. Han, C.N. Svendsen, Regionally specified human neural progenitor cells derived from the mesencephalon and forebrain undergo increased neurogenesis following overexpression of ASCL1, Stem. Cells 27 (2009) 390-398.

[59] J.B. Jensen, M. Parmar, Strengths and limitations of the neurosphere culture system, Mol. Neurobiol. 34 (2006) 153-161.

[60] J. Yan, L. Studer, R.D. McKay, Ascorbic acid increases the yield of dopaminergic neurons derived from basic fibroblast growth factor expanded mesencephalic precursors, J. Neurochem. 76 (2001) 307-311.

[61] L. Roybon, T. Hjalt, N.S. Christophersen, J.Y. Li, P. Brundin, Effects on differentiation of embryonic ventral midbrain progenitors by Lmx1a, Msx1, Ngn2, and Pitx3, J. Neurosci. 28 (2008) 3644-3656.

[62] N.S. Christophersen, X. Meijer, J.R. Jorgensen, U. Englund, M. Gronborg, A. Seiger, P. Brundin, L.U. Wahlberg, Induction of dopaminergic neurons from growth factor expanded neural stem/progenitor cell cultures derived from human first trimester forebrain, Brain Res. Bull. 70 (2006) 457-466.

[63] T. Kallur, V. Darsalia, O. Lindvall, Z. Kokaia, Human fetal cortical and striatal neural stem cells generate region-specific neurons in vitro and differentiate extensively to neurons after intrastriatal transplantation in neonatal rats, J. Neurosci. Res. 84 (2006) 1630-1644.
[64] E. Cacci, A. Villa, M. Parmar, M. Cavallaro, N. Mandahl, O. Lindvall, A. Martinez-Serrano, Z. Kokaia, Generation of human cortical neurons from a new immortal fetal neural stem cell line, Exp. Cell Res. 313 (2007) 588-601.

[65] N. Osumi, H. Shinohara, K. Numayama-Tsuruta, M. Maekawa, Concise review: Pax6 transcription factor contributes to both embryonic and adult neurogenesis as a multifunctional regulator, Stem. Cells 26 (2008) 1663-1672.

[66] Z. Mo, N. Zecevic, Is Pax6 critical for neurogenesis in the human fetal brain?, Cereb. Cortex 18 (2008) 1455-1465.

[67] X. Zhang, C.T. Huang, J. Chen, M.T. Pankratz, J. Xi, J. Li, Y. Yang, T.M. Lavaute, X.J. Li, M. Ayala, G.I. Bondarenko, Z.W. Du, Y. Jin, T.G. Golos, S.C. Zhang. Pax6 is a human neuroectoderm cell fate determinant, Cell Stem. Cell 7 (2010) 90-100.

[68] B. Vernay, M. Koch, F. Vaccarino, J. Briscoe, A. Simeone, R. Kageyama, S.L. Ang, Otx2 regulates subtype specification and neurogenesis in the midbrain, J. Neurosci. 25 (2005) $4856-4867$

[69] S.A. Bayer, K.V. Wills, L.C. Triarhou, B. Ghetti, Time of neuron origin and gradients of neurogenesis in midbrain dopaminergic neurons in the mouse, Exp. Brain Res. 105 (1995) 191-199.

[70] T.B. Freeman, M.S. Spence, B.D. Boss, D.H. Spector, R.E. Strecker, C.W. Olanow, J.H. Kordower, Development of dopaminergic neurons in the human substantia nigra, Exp. Neurol. 113 (1991) 344-353.

[71] P.M. Almqvist, E. Akesson, L.U. Wahlberg, H. Pschera, A. Seiger, E. Sundstrom, First trimester development of the human nigrostriatal dopamine system, Exp. Neurol. 139 (1996) 227-237.

[72] F.J. Rubio, C. Bueno, A. Villa, B. Navarro, A. Martinez-Serrano, Genetically perpetuated human neural stem cells engraft and differentiate into the adult mammalian brain, Mol. Cell Neurosci. 16 (2000) 1-13.

[73] T. Perlmann, A. Wallen-Mackenzie, Nurr1, an orphan nuclear receptor with essential functions in developing dopamine cells, Cell Tissue Res. 318 (2004) 45-52.

[74] C. Martinat, J.J. Bacci, T. Leete, J. Kim, W.B. Vanti, A.H. Newman J.H. Cha, U. Gether, H. Wang, A. Abeliovich, Cooperative transcription activation by Nurr1 and Pitx3 induces embryonic stem cell maturation to the midbrain dopamine neuron phenotype, Proc. Nat. Acad. Sci. U.S.A. 103 (2006) 2874-2879.

[75] M.P. Smidt, C.H. Asbreuk, J.J. Cox, H. Chen, R.L. Johnson, J.P. Burbach, A second independent pathway for development of mesencephalic dopaminergic neurons requires Lmx1b, Nat. Neurosci. 3 (2000) 337-341.

[76] W. Lin, E. Metzakopian, Y.E. Mavromatakis, N. Gao, N. Balaskas, H. Sasaki, J. Briscoe, J.A. Whitsett, M. Goulding, K.H. Kaestner, S.L. Ang, Foxa1 and Foxa2 function both upstream of and cooperatively with $L m x 1 a$ and $L m x 1 b$ in a feedforward loop promoting mesodiencephalic dopaminergic neuron development, Dev. Biol. 333 (2009) 386-396.

[77] E. Arenas, Foxa2: the rise and fall of dopamine neurons, Cell Stem. Cell 2 (2008) 110-112.

[78] E. Garcia-Garcia, M.J. Pino-Barrio, L. Lopez-Medina, A. MartinezSerrano, Intermediate progenitors are increased by lengthening of the cell cycle through calcium signaling and p53 expression in human neural progenitors, Mol. Biol. Cell 23 (2012) $1167-1180$ 